\title{
Comprehensive Insight of Neurodegenerative Diseases and The Role of Neurotoxin Agents — Glutamate
}

\author{
Hui-Min Yap ${ }^{1 *}$, Kwan-Liang Lye ${ }^{1}$, Loh Teng-Hern Tan ${ }^{2}$ \\ ${ }^{1}$ Department of Biomedical Sciences Faculty of Medicine and Health Sciences, Universiti Putra Malaysia, 43400 UPM \\ Serdang, Selangor Darul Ehsan, Malaysia \\ ${ }^{2}$ Novel Bacteria and Drug Discovery Research Group (NBDD), Microbiome and Bioresource Research Strength (MBRS), \\ Jeffrey Cheah School of Medicine and Health Sciences, Monash University Malaysia, 47500 Bandar Sunway, Selangor \\ Darul Ehsan, Malaysia
}

\begin{abstract}
The increased concentration of extracellular glutamate has been reported to play a key role in most of the neurodegenerative diseases, such as Parkinson's disease and Alzheimer's disease, even though its importance as an amino acid neurotransmitter in mammalian. Glutamate toxicity, which can be caused by excessive intake of monosodium glutamate (MSG), is the major contributor to pathological neuronal cell death. It causes neuronal dysfunction and degeneration in the central nervous system (CNS). Glutamate neurotoxicity can be categorized into two forms, which are receptor-mediated glutamate excitotoxicity and non-receptor mediated glutamate oxidative toxicity. The receptor-mediated glutamate excitotoxicity involved excessive stimulation of glutamate receptors (GluRs) which lead to excessive ion calcium $\left(\mathrm{Ca}^{2+}\right)$ influx and activates a cell death cascade involving the accumulation of mitochondrially generated reactive oxygen species (ROS). Studies showed excessive extracellular glutamate leads to nerve cell death via the activation of $N$-methyl-Daspartate (NMDA) receptors in the cases of trauma or stroke. Whereas non-receptor mediated oxidative toxicity involved the breakdown of the cystine/glutamate antiporter $\left(\mathrm{x}_{\mathrm{c}}^{-}\right)$mechanism, which leads to the depletion of glutathione (GSH) and causes oxidative stress and cell death. The cystine/glutamate antiporter couples the import of cystine to the export of glutamate.

The increased concentration of extracellular glutamate could inhibit the uptake of cystine, which is required for the synthesis of the intracellular antioxidant GSH. GSH plays an important role in the disposal of peroxides by brain cells and in the protection against ROS. Depletion of GSH renders the cell to oxidative stress and ultimately leading to cell death. This article aims to provide a comprehensive review of neurodegenerative diseases and the role of neurotoxin agents, glutamate in these diseases.
\end{abstract}

Keywords: neurodegenerative diseases; Alzheimer's disease; Parkinson's disease; neurotoxin agents; glutamate

*Correspondence: Hui-Min Yap, Department of Biomedical

Received: $18^{\text {th }}$ April 2020 Sciences Faculty of Medicine and Health Sciences, Universiti

Accepted: $19^{\text {th }}$ April 2020 Putra Malaysia, 43400 UPM Serdang, Selangor Darul Ehsan,

Published Online: $22^{\text {nd }}$ April 2020 Malaysia; huimin050686@gmail.com.

Citation: Yap, H.M, Lye K-L and Tan LT-H. Comprehensive insight of neurodegenerative diseases and the role of neurotoxin agents — Glutamate. Prog Mircobes Mol Bio1 2020; 3(1): a0000070. https://doi.org/10.3687/pddbs.a0000070

\section{INTRODUCTION}

\section{Nervous System}

Nervous system is the major controlling, regulatory and communicating system in the body responsible for receiving and transmitting stimuli throughout the body ${ }^{[1]}$. Nervous system also monitors and coordinates internal organ function and initiates response to the changes in the external environment. Nervous system can be divided into central nervous system (CNS) and peripheral nervous system (PNS). CNS is composed of the brain and spinal cord, which serves as the main processing center for the entire nervous system ${ }^{[2]}$. It receives information from and sends information to the PNS. PNS is made up of all the nerves connecting the body to the brain and spinal cord. Sensory neuron is responsible in sending information from internal organ or from external stimuli to CNS, whereas motor neuron transmits information from CNS to organs, muscles and glands ${ }^{[2]}$. The motor nervous system can be further divided into two systems; autonomic nervous system and somatic nervous system. Autonomic nervous system is responsible for involuntary or visceral bodily function while somatic nervous system is mediating voluntary reflexes for instance skeletal muscle. In general, activity of the nervous system depends on the connectivity among two cell types, which are neurons and glia ${ }^{[3-5]}$. 


\section{Neuronal Cell}

Neuronal cell is an excitable nerve cell that processes and transmits information by electrochemical signaling. Most neurons cannot divide; thus, neurons cannot be replaced if lost due to injury or disease ${ }^{[1]}$. There are 3 types of neurons based on functions, which are sensory neurons, motor neurons, and interneuron. Interneurons carry information between sensory neurons and motor neurons and can be found in CNS.

Generally, neuronal cell is comprised of neuronal cell body (soma), axon and dendrite. The axon has a terminal end that constitutes the pre-synaptic site of the synapse while the dendrite has an apical site and multiple branches. Neuron communicates with each other at synaptic cleft (synapse), which involved release of neurotransmitter by pre-synaptic cell and binding of neurotransmitter to the receptor on post-synaptic cell. Neurotransmitter will trigger an electrical response or a secondary messenger pathway that may either excite or inhibit postsynaptic neuron $^{[4]}$. Excitatory neurotransmitter causes changes that generate action potential in the responding neuron while inhibitory neurotransmitter will block the changes ${ }^{[6,7]}$. Major neurotransmitters found in the body include glutamate, dopamine, glycine, gamma-aminobutyric acid (GABA) and serotonin.

\section{Glial Cell}

The glial cells provide vital support for the proper functioning of neurons. Glial cells are also known as nerve glue, are non-neuronal cells of the nervous system. It does not transmit electrical impulses, but it appears to be the most abundant cell types in the CNS. Glial cell can be divided into macroglia (astrocytes, oligodendroglia and Schwann cells) and microglia. Different types of glial cell provide different support to neurons. Microglia cells in CNS protect neurons from bacteria invasion. Oligodendrocytes and Schwann cells provide myelination to axons in CNS and PNS respectively. Myelin sheath provides insulation to the axon that allows electrical signals to be transmitted efficiently ${ }^{[8]}$. Astrocytes not only provide physical support to neurons, but also support neurons by providing antioxidant protection, substrates for neuronal metabolism via neurovascular coupling, digest dead neurons and glutamate clearances ${ }^{[4,9]}$. Also, astrocytes have interaction with the cerebral endothelium in determining blood brain barrier function, morphology and protein expression ${ }^{[10]}$.

\section{Neuron-astrocyte interaction in the brain}

Astrocytes are the most numerous and diverse glial cells in the CNS. Many studies demonstrating astrocyte dysfunction throughout the neurodegenerative process as a prominent determinant for survival for both neuronal cell and the entire organism. Neuronal activity leads to increase of potassium ion $\left(\mathrm{K}^{+}\right)$and glutamate levels in extracellular space. As a supportive cell, astrocyte plays important role in maintaining the extracellular $\mathrm{K}^{+}$ homeostasis through potassium channels expressed by astrocytes $^{[11]}$. Moreover, astrocytes are known to express high level of glutamate transporter to remove glutamate from extracellular space ${ }^{[12]}$. The increased concentration of extracellular $\mathrm{K}^{+}$and glutamate will trigger astrocyte glycolysis and further enhance lactate and pyruvate production to fuel neuronal tricarboxylic acid cycle (TCA cycle $)^{[13,14]}$. Astrocyte and neuronal cell also coupled by glutamate-glutamine cycle. Astrocytes take up glutamate and convert it to glutamine. This glutamine is then shuttled back to presynaptic terminals (neuronal cells) and used by neuronal cell to replenish the neurotransmitter glutamate ${ }^{[15]}$. In addition, neurotransmitters released by neuronal cells induce transient elevations of internal $\mathrm{Ca}^{2+}$ levels in astrocytes due to the activation of metabotropic glutamate receptors on astrocytes ${ }^{[16,17]}$. The increased level of astrocytic $\mathrm{Ca}^{2+}$ triggers the release of chemical transmitters from astrocytes, which can cause sustained modulatory actions on neighbouring neuronal cells ${ }^{[17]}$.

\section{NEURODEGENERATIVE DISEASES}

Neurodegenerative diseases are becoming huge public health challenge due to their increasing medical and social impact. It is one of the major global health burdens in the Western world and is often found in aging population $^{[18]}$. These diseases can be life-threatening and have great impacts on both the patients and caregivers. Neurodegenerative diseases can be illustrated by progressive nervous system dysfunction that causes deterioration of many of human body's activities, including speech, movement, balance, heart function and breathing ${ }^{[19]}$. The causes of neurodegenerative diseases comprise genetic factors, infections or autoimmune diseases, brain trauma or injury and environmental toxins $^{[20-23]}$. Most of the neurodegenerative disorders are incurable; thus, treatments are applied with the hope to relieve pain, improve symptoms, and increase mobility. Neurodegenerative diseases are categorized based on primary brain region or type of affected brain cell, clinical symptoms, and type of protein aggregated in brain ${ }^{[24]}$. Parkinson's disease (PD), Alzheimer's disease (AD), and amyotrophic lateral sclerosis (ALS) are the most common age-related neurodegenerative diseases. Some forms of these diseases could be inherited. Moreover, morphological, biochemical, genetic, cell and animal model studies reveal that mitochondria play roles in the neurodegeneration through rendering vulnerable neurons susceptible to stress, cellular aging and genetic variations ${ }^{[25]}$.

\section{Alzheimer's Disease (AD)}

Alzheimer's disease (AD) can be categorized by progressive degenerative disorders of the brain which causes irreversible loss of neurons and memory. It is one of the common causes leading to dementia. Late-onset of Alzheimer's disease (LOAD) with age 65 years or older is representing the majority of AD. Senile plaques, intracellular neurofibrillary tangles (NFTs), extracellular degenerating neurons, dystrophic neuritis, and activated 
astrocytes or microglial found in the brain underlie the pathogenesis of $\mathrm{AD}^{[26]}$. Senile plaque is mainly composed of $\beta$-amyloid $(A \beta)$ while NFTs consist of hyperphosphorylated and aggregated forms of the tau protein. Tau is a microtubule-binding protein that acts as neuronal cytoskeleton stabilizer and participates in vesicular transport and axonal polarity. The deposition of hyperphosphorylated tau protein impairs axonal transport therefore affecting the nutrition of dendrites and axon terminals. While the accumulation of $\mathrm{A} \beta$ activates cellular stress responses and disrupts signal transduction pathways ${ }^{[27]}$. Studies indicated that $\mathrm{A} \beta$ also induces inflammatory reaction in the brain and causes release of various cytokine such as TNF- $\alpha$ (tumor necrosis factoralpha $)^{[28]}$. TNF- $\alpha$ could induce infiltration of leukocytes and possible T-cells into the central nervous system through its capacity in enhancing blood brain barrier permeability ${ }^{[29]}$. The increased permeability of blood brain barrier causes influx of neurotoxin, such as glutamate and arachidonic acid, which could lead to substantial damage to the brain. Cholinergic and glutamatergic neurotransmission systems, which play role in cognition, were affecting in patients with Alzheimer's disease ${ }^{[30]}$.

\section{Parkinson's Disease (PD)}

Parkinson's disease (PD) is the second most common latelife neurodegenerative disease after Alzheimer's disease. It can be characterized by progressive dopaminergic cell loss in the substantia nigra pars compacta which leads to dysfunction of the basal ganglia system and motor symptoms and subsequently causing tremors, slow movement, rigidity and gait impairment ${ }^{[31,32]}$. Another pathological feature of PD is the accumulation of Lewy bodies in neurons of the brainstem nuclei, substantia nigra, hippocampus, cerebral cortex, myenteric plexus, and olfactory bulb. Lewy bodies are accumulations of microscopic protein deposits in the brain, mainly alpha-synuclein. The pathology of PD is not yet fully understood. Some genetic and toxin-based animal models suggest that inflammation, oxidative stress, mitochondrial dysfunction, aberrant processing of proteins by the ubiquitin-proteasome system, and activation of apoptotic pathways are playing roles in dopaminergic cell death ${ }^{[33]}$. Furthermore, some studies indicated the increased glutamatergic transmission may contribute an excitotoxic component to the cellular insults that lead to degeneration in the substantia nigra pars compacta as well as the glial response that arises in the striatum and the substantia nigra $^{[34]}$.

\section{Other Neurodegenerative Diseases}

Other neurodegenerative disorders include Huntington's disease (HD) and amyotropic lateral sclerosis (ALS). HD can be categorized by cognitive decline, psychiatric disturbances and motor dysfunction, which will lead to dementia and death approximately 15-20 years after the onset of the disease ${ }^{[35]}$. HD is an autosomal-dominant disorder caused by the expansion of a CAG trinucleotide repeat encoding an abnormally long polyglutamine track in the $\mathrm{N}$ terminus of the huntingtin protein ${ }^{[36]}$. This protein may inhibit mitochondrial function and proteasome activity $^{[37]}$. HD has a prevalence of 5-10 cases per 100,000 . Thus, HD is known as one the most common inherited neurodegenerative disease ${ }^{[35]}$.

While amyotrophic lateral sclerosis seemed to be a progressive and usually fatal disorder caused by motorneuron degeneration in the brain and spinal cord. Motorneuron degeneration in the brain and spinal cord will lead to paralysis of voluntary muscles. The mutation in superoxide dismutase 1 (SOD1) seems to be associated with amyotrophic lateral sclerosis. This mutation will form aggregates in mitochondria which could interfere anti-apoptotic function of B-cell lymphoma 2 (Bcl-2), mitochondrial import and generate free radicals. Reactive oxygen species produced will inhibit the function of glial glutamate transporter (EAAT2) and lead to the increase of extracellular glutamate, next triggering motor neuron death ${ }^{[38]}$.

\section{FACTORS INVOLVED INNEURODEGENERATIVE DISEASES}

Neurodegeneration is due to the death of neuronal cells through the delayed process of apoptosis or necrosis. Among the known risk factors for neurodegenerative diseases, such as genetic polymorphism, infection and head trauma, the role of neurotoxin agents such as glutamate and an oxidative stress received huge attention recently. This is because most of the pathologies of neurodegenerative diseases involve oxidative stress triggered by neurotoxin agents or imbalance in pro-oxidant/antioxidant homeostasis ${ }^{[39,40]}$.

\section{Astrocytes in Neurodegenerative Diseases}

Astrocytes have many housekeeping functions, such as the maintenance of the extracellular environment and synaptic function in the CNS. Also, astrocytes play a vital role in the maintenance of neurotransmitter synthesis and neuronal metabolism. Astrocytes become activated (reactive) in response to a variety of brain insults, such as trauma, stroke and neurodegenerative disease ${ }^{[41]}$. Reactive gliosis can be characterized by the increase expression of vimentin (Vim), glial fibrillary acidic protein (GFAP), S100 $\beta$ and proliferation that could probable occur in neurodegenerative diseases ${ }^{[42]}$. Astrocytes will be activated under stress and injury, leading to an upregulation of proinflammatory cytokines and chemokines, which are related to the pathogenesis of $\mathrm{AD}^{[43]}$. Recent studies suggested that activated astrocytes play a role in the clearance of the $A \beta$-peptide and thus preventing the plaque formation in $\mathrm{AD}$. Furthermore, astrocytosis (abnormal increase number of astrocytes) was discovered in affected brain region of HD patients. The Huntingtin protein was also observed to be co-localized with reactive astrocytes $^{[15]}$.

\section{GLUTAMATE}

L-glutamate is a non-essential amino acid which can be gained from alimentary protein, endogenous protein and 
also monosodium glutamate (MSG) that is used as food additive ${ }^{[44]}$. It is one of the most abundant neurotransmitter in mammalian central nervous system and it is involved in numerous normal brain functions, such as memory, cognition and learning ${ }^{[45]}$. Furthermore, glutamate has an essential role in regulating bio-energetic processes such as reactions of glycolysis, gluconeogenesis, citric acid cycle and synthesis of ketone bodies. It is the precursor for $\gamma$-aminobutyric acid (GABA) and glutathione (GSH) [46]. Glutamate is one of the key factors in central pain transduction mechanisms and excitotoxic neuronal cell injury ${ }^{[45]}$

\section{Glutamate receptors}

Neurotransmission occurs at synapses and it involved processes of neurotransmitters carrying signals released from presynaptic neuron terminals to synaptic cleft followed by binding of neurotransmitter to the receptors on the postsynaptic neuron. Binding of excitatory neurotransmitters, such as glutamate, to the receptor proteins on the postsynaptic neuron will cause sodium ion $\left(\mathrm{Na}^{+}\right)$channels to open and allow influx of $\mathrm{Na}^{+}$to neuronal cell, and causes the neuron membrane to depolarize due to an action potential. The excitation of glutamate can be mediated via activation of metabotropic glutamate receptors and ionotropic glutamate receptors ${ }^{[47]}$. There are 3 families of ionotropic glutamate receptors; $N$-Methyl-D-Aspartate (NMDA), $\alpha$-amino-3-hydroxyl-5-methyl-4-isoxazole-propionate (AMPA) and kainate receptors. The ionotropic glutamate receptors are coupled directly to membrane ion channels which conducting only $\mathrm{Na}^{+}$or both $\mathrm{Na}^{+}$and $\mathrm{Ca}^{2+}$. Metabotropic glutamate receptors comprise of G-protein coupled receptors (mGluR1-8) that are important in regulating ion channels and enzymes producing second messenger ${ }^{[48]}$. It is categorized into 3 groups based on the sequence, function and pharmacology. Group I mGluRs (mGluR1 and 5) activates phospholipase C via $\mathrm{Gq}$ proteins and initiate an inositol triphosphate/ diacylglycerol (IP3/DAG) second messenger cascade. Whereas Group II mGluRs (mGluR2 and 3) and Group III mGluRs (mGluR4, 6, 7 and 8) inhibit adenylyl cyclase via Gi/o proteins. Reports showed that group II and III were mainly localized on presynaptic neuron while group III was localized on postsynaptic neuron ${ }^{[49]}$. Metabotropic and Ionotropic glutamate receptors present on both neuronal and glial cells ${ }^{[50,51]}$. Nevertheless, the involvement of glutamate receptors of glial cells in neurotransmission remains unknown. While the binding of inhibitory neurotransmitters, such as serotonin or GABA, to the receptor proteins on the postsynaptic neuron will lead to hyperpolarization and efflux of potassium ion $\left(\mathrm{K}^{+}\right)$from neuronal cell ${ }^{[52]}$.

\section{Glutamate Transporters}

The level of extracellular glutamate must remain low to prevent excessive excitation that can injure or kill neuronal cells due to the deficiency of enzyme at extracellular space to metabolize glutamate. The excessive glutamate can only be removed by cellular uptake through glutamate transporters on the plasma membrane of astrocytes and neuronal cells. Glutamate transporter can be discovered in the plasma membranes and intracellular membrane ${ }^{[53]}$. Glutamate transporters in the plasma membranes can be categorized into high affinity glutamate transporters and low affinity glutamate transporters. There are 5 high affinity glutamate transporters, also known as sodium-dependent glutamate transporters, have been cloned, namely excitatory-amino acid transporter 1-5 (EAAT1-5). These 5 glutamate transporters catalyze $\mathrm{Na}^{+}$- and $\mathrm{K}^{+}$-coupled transport of L-glutamate and also L- and D-aspartate ${ }^{[54]}$. Each glutamate is co-transported with two or three $\mathrm{Na}^{+}$and counter-transport of one $\mathrm{K}^{+[55]}$. EAAT3, EAAT4 and EAAT5 are known as neuronal glutamate transporters. However, there were studies that showed EAAT4 was expressed in astrocytes as well[56]. EAAT1 and EAAT2, also known as glutamate aspartate transporter (GLAST) and glutamate transporter-1 (GLT1) respectively, are expressed in astrocytes ${ }^{[57]}$. These astrocytic glutamate transporters are responsible for the majority of glutamate uptake near excitatory synapse ${ }^{[58,59]}$.

Cystine/glutamate antiporter (system xc') is a low affinity glutamate transporter which also known as sodiumindependent glutamate transporter. System $\mathrm{xc}^{-}$is composed of two subunits, which are $\mathrm{xCT}$ light chain and 4F2 heavy chain. It is also known as cystine transporter which carries cystine into the cell in exchange for internal glutamate by using the transmembrane gradient of glutamate as driving force ${ }^{[54,60]}$. This system is suggested to mediate the cellular cystine uptake for the synthesis of GSH and maintenance of cystine-cysteine redox balance in the extracellular compartment, which is vital for the cellular protection from oxidative stress and cell death ${ }^{[61]}$.

\section{Glutamate Metabolism}

When glutamate taken up by cells, it is not only used as transmitter, but also used for metabolic purposes such as protein synthesis, energy metabolism and ammonia fixation $^{[62]}$. In the nerve terminal, cytoplasmic glutamate is transported into synaptic vesicles by vesicular glutamate transporters (VGLUTs) and then released to the synaptic cleft by exocytosis. As neurotransmitter, the binding of a transmitter to postsynaptic ionotropic glutamate receptors (AMPA, NMDA and kainate receptors) will cause an ionic influx that depolarizes the neuron (excitation) ${ }^{[63]}$. Whereas, a slower second messenger-mediated affects occur following the activation of the metabotropic glutamate receptors by glutamate ${ }^{[64]}$. To avoid excessive excitation that could injure and damage neurons, glutamate in the synapse should be removed rapidly. Glutamate can be removed via the uptake into the postsynaptic compartment, uptake into nonneuronal compartment (astrocyte) and reuptake into the presynaptic compartment. Glutamate uptake into presynaptic and postsynaptic neurons seems to be less important than astrocytic transport due to the membrane potential of astrocytes lower than neurons ${ }^{[65]}$. In astrocytes, glutamate taken up from extracellular fluid is metabolized by 2 different pathways, which are 
tricarboxylic acid cycle (TCA cycle) and glutamateglutamine cycle. Astrocytes convert glutamate and ammonia to glutamine (non-neuroactive species) via ATPdependent glutamine synthetase. This pathway further supports the buffering of ammonia, which is a potential neurotoxic species. Glutamine synthetase in the brain is located mostly in astrocytes ${ }^{[66]}$. Glutamine produced is then released to the extracellular fluid and taken up by neuronal cell. Glutamine taken up into neuronal cell could be hydrolyzed to glutamate and ammonia via the action of phosphate-dependent glutaminase. The regenerated glutamate will be reused as neurotransmitter or potential fuel by being oxidized to $\alpha$-ketoglutarate for neuronal cells ${ }^{[67,68]}$.

Meanwhile, glutamate taken up by astrocyte could be converted to $\alpha$-ketoglutarate and ammonia via reversible dehydrogenation by glutamate dehydrogenase (GDH) with either $\mathrm{NAD}^{+}$or $\mathrm{NADP}^{+}$as a cofactor ${ }^{[69]}$. Alpha-ketoglutarate is metabolized through TCA cycle to succinate, fumarate and malate. Malate is further decarboxylated to pyruvate and reduced to lactate. Both pyruvate and lactate are exported from astrocytes to the extracellular fluid and taken up by neuronal cell. Furthermore, glutamate uptake into astrocytes will stimulate glycolysis, that is glucose utilization and lactate production. Glutamate activates astrocytic $\mathrm{Na}^{+} / \mathrm{K}^{+}$ ATPase by cotransport $\mathrm{Na}^{+}$into the cell via $\mathrm{Na}^{+}$-dependent glutamate uptake by glutamate transporters. The resulted lactate will provide the fuel for neuronal TCA cycle ${ }^{[70]}$. Figure 1 denotes the metabolism of glutamate in neuronal cell and astrocyte.

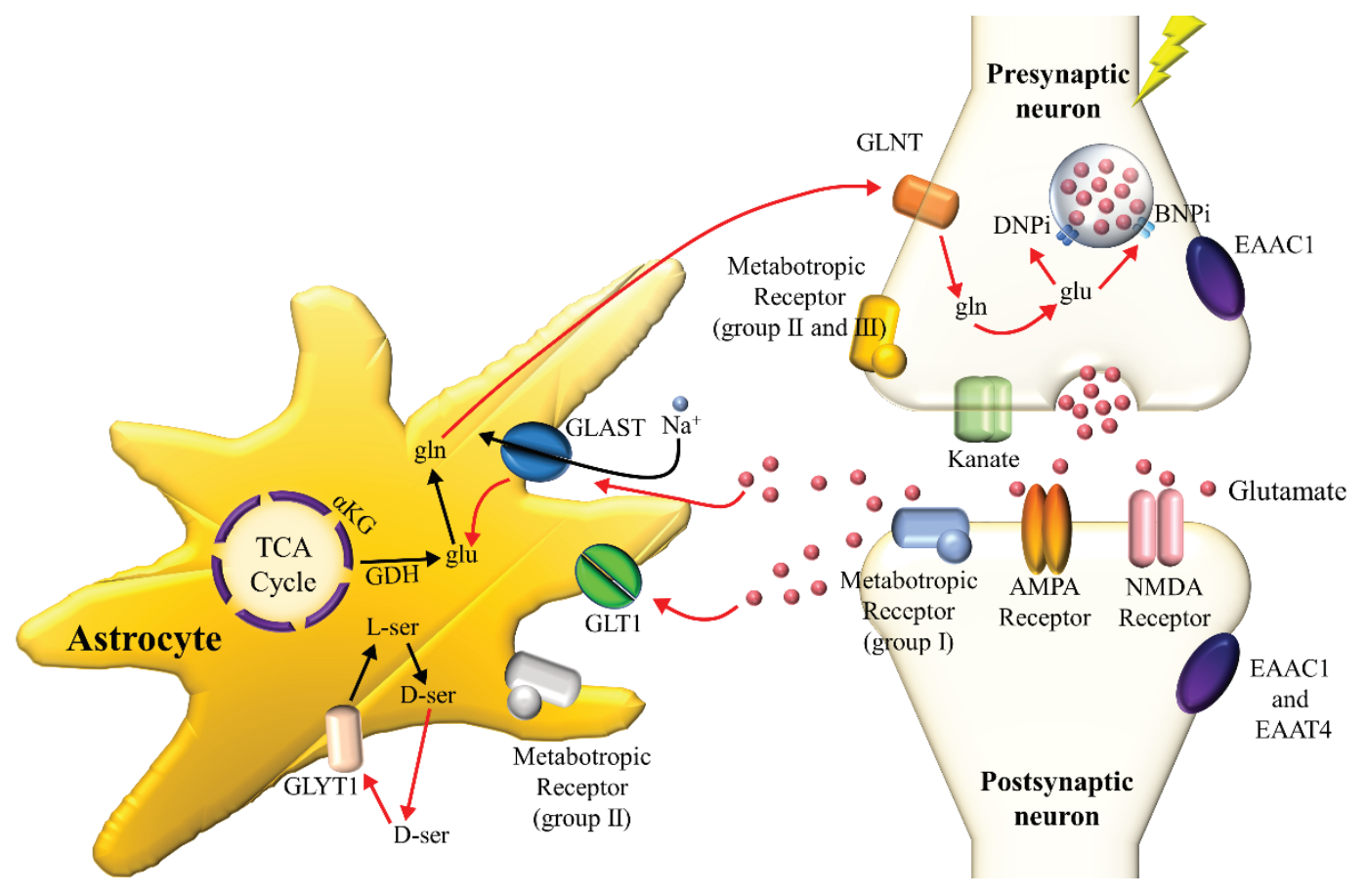

Figure 1. Glutamate metabolism in neuronal cell and astrocyte.

\section{Glutamate Neurotoxicity}

The maintenance of a low level $(1-3 \mu \mathrm{M})$ of extracellular glutamate is vital for normal brain function to prevent excessive stimulation of receptors, excessive formation of ammonia by glutamate dehydrogenase and breakdown of glutamate/cystine antiporter. The excessive accumulation of extracellular glutamate is the main contributor to neuronal cell death under pathological conditions for instance ischemic insults and traumatic brain damage which could be associated to the disruption of glutamate metabolism ${ }^{[71,72]}$. The disruptions of glutamate metabolism underlie many neurodegenerative pathologies, for instance Alzheimer's disease, Parkinson's disease, Huntington's disease, brain ischemia and amyotrophic lateral sclerosis. These may be associated to variation of glutamate metabolism enzyme activities, disruption in mitochondrial homeostasis, and oxidation or redox imbalance in cells ${ }^{[73,74]}$. Glutamate neurotoxicity can be classified into receptor-mediated glutamate excitotoxicity and non-receptor mediated oxidative glutamate toxicity.

\section{Receptor-Mediated Glutamate Excitotoxicity}

Hayashi was the first to discover the excitatory action of glutamate in 1952 by injecting glutamate into mammalian brain able to produce convulsion ${ }^{[75]}$. Toxicity of glutamate was then observed when the injection of monosodium glutamate destroyed the neurons in the inner layers of the retina and induced acute neuronal necrosis in brain and term as excitotoxicity ${ }^{[7-78]}$. Elevated concentration of extracellular glutamate will cause excessive stimulation of glutamate receptors at postsynaptic membrane, which will further induce excessive influx of $\mathrm{Ca}^{2+}$ and $\mathrm{Na}^{+}$. Ionotropic glutamate receptors directly activate channels that allow influx of extracellular $\mathrm{Ca}^{2+}$ and $\mathrm{Na}^{+}$while metabotropic glutamate receptor stimulates calcium released from internal store (endoplasmic reticulum and mitochondria) [79,80]. The influx of $\mathrm{Ca}^{2+}$ and $\mathrm{Na}^{+}$through glutamate receptor activation will result in membrane depolarizations which further activate voltage-dependent calcium channels. Plasma membrane calcium transporters regulate the calcium homeostasis by maintaining low concentration of 
free intracellular calcium relative to free extracellular. Basically, there are 3 types of membrane transporters, namely antiporters, symporters and ATP-coupled active transporters. Calcium is controlled by the antiporters and $\mathrm{Ca}^{2+}$-ATPase. Antiporters and $\mathrm{Ca}^{2+}$-ATPase move $\mathrm{Ca}^{2+}$ out of the neuron and restore $\mathrm{Ca}^{2+}$ to mitochondria and endoplasmic reticulum ${ }^{[81]}$. Antiporter transport $\mathrm{Ca}^{2+}$ by a sodium-calcium exchange mechanism while the $\mathrm{Ca}^{2+}$ ATPase transports one $\mathrm{Ca}^{2+}$ for each ATP hydrolyzed with a resultant increase in ATP demand. In addition, the direct uptake of $\mathrm{Ca}^{2+}$ into the matrix utilizes the proton circuit for oxidation phosphorylation and competes with mitochondrial ATP synthesis ${ }^{[82]}$. Therefore, mitochondrial ATP synthesis in mitochondria may cease as the $\mathrm{Ca}^{2+}$ flood from cytoplasm to the matrix ${ }^{[83]}$. Moreover, there are studies that showed $\mathrm{Ca}^{2+}$ influx from extracellular space activates cytosolic phospholipase A2 and lead to production of arachidonic acid ${ }^{[84,85]}$. ROS will be created during arachidonic acid oxidative metabolism ${ }^{[86]}$.

$\mathrm{Ca}^{2+}$ excess of mitochondrial matrix triggers a mitochondrial permeability transition pore opens in the mitochondrial membrane, which will lead to collapse of mitochondrial membrane potential (MMP)

[87]. Furthermore, reactive oxygen species formed from oxidation phosphorylation also contribute to the opening of the mitochondrial permeability transition pore ${ }^{[88]}$. The maintenance of MMP is vital for ATP synthesis. The collapse of MMP is related to a secondary increase in cytosolic $\mathrm{Ca}^{2+}$ concentration and the release of cytochrome $c$ followed by caspase activation and apoptosis $^{[89]}$. Moreover, caspase-independent death can also be induced by MMP through release of caspaseindependent death effectors such as apoptosis-inducing factor and endonuclease $\mathrm{G}^{[00]}$.

\section{Non-Receptor Mediated Glutamate Oxidative Toxicity}

The increased concentration of extracellular glutamate will lead to a prolonged cell death by oxidative stress known as glutamate oxidative toxicity. In glutamate oxidative toxicity, increased concentration of extracellular glutamate interferes with cystine uptake by blocking the glutamate gradient driven cystine/ glutamate antiporter $\left(\text { system } \mathrm{xc}^{-}\right)^{[91]}$. In facilitating the uptake of cystine, it is vital to exchange with glutamate at an equimolar ratio. The breakdown of system $\mathrm{xc}^{-}$will lead to the depletion of cystine and glutathione (GSH). In normal situation, imported cystine (oxidized form of 2 cysteines) is reduced to cysteine, which primarily acts as a precursor for GSH synthesis. The depletion of GSH renders the cells to oxidative stress and cell death ${ }^{[92]}$. Studies indicated that GSH depletion lead to activation of 12-lipoxygenase (12-LOX) and 15-lipoxygenase (15-LOX) and also causes inactivation of GSH peroxidase $4(\mathrm{Gpx} 4)$, which damage mitochondria and resulted to cytochrome $c$ and apoptosis-inducing factor (AIF) release, followed by reactive oxygen species accumulation and cell death ${ }^{[93-96]}$.

\section{OXIDATIVE STRESS}

Oxidative stress built up caused by an imbalance of free radicals (pro-oxidant) and antioxidants in favor of the former. Free radicals are atoms or groups of atoms that have one or more unpaired electrons which make it extremely reactive ${ }^{[97]}$. These extremely reactive molecules tend to react quickly with adjacent molecules by donating or capturing an electron in order to gain stability and start the free radical reaction chain. It usually arises during body normal metabolism and increase with age. Also, free radicals can be generated by the immune system to destroy bacteria and viruses during infection. Environmental factors for instance pollution and radiation can further increase the production of free radicals. The most common cellular free radicals include hydrogen peroxide $\left(\mathrm{H}_{2} \mathrm{O}_{2}\right)$, hydroxyl $(\mathrm{OH} \cdot)$, superoxide $\left(\mathrm{O}_{2}^{-}\right)$and nitric monoxide $(\mathrm{NO} \cdot)$. High level of free radicals leads to redox imbalance and oxidative damage to biomolecules, such as protein, lipids and DNA, then lead to many chronic diseases in human such as cancer, diabetics, atherosclerosis, postischemic perfusion injury, cardiovascular diseases, stroke, chronic inflammation and other degenerative diseases ${ }^{[98]}$.

Reactive oxygen species (ROS) and the reactive nitrogen species (RNS) are extremely reactive among free radicals, which acts as mediators in biological processes for instance respiration, cellular metabolism, gene translation and transcription, neurotransmission and inflammatorytype reactions ${ }^{[99]}$. Mitochondria are the main contributor to ROS production, and the electron transport chain that is found in the inner mitochondrial membrane uses oxygen to produce adenosine triphosphate (ATP) ${ }^{[100]}$. Cytochrome oxidase functions as the terminal enzyme of the chain by accepting an electron from cytochrome $c$ and transferring it to oxygen (the final electron acceptor in the chain). The reduction of oxygen by one electron at a time by cytochrome oxidase make it becomes highly reactive. Superoxide $\left(\mathrm{O}_{2}^{-}\right)$, the product of one-electron reduction of oxygen, occurs mainly within the mitochondria of a cell[ ${ }^{[101]}$. It also functions as the precursor of ROS (such as hydroxyl radical) and as a mediator in oxidative chain reactions ${ }^{[102]}$. ROS is known to initiate lipid peroxidation by targeting the carbon-carbon double bond of polyunsaturated fatty acids (PUFAs) which are ample in cellular membranes and lowdensity lipoproteins. High level of oxygen requirement and unsaturated lipids in brain make it particularly susceptible to oxidative damage and lipid peroxidation ${ }^{[103,104]}$. Neuronal cells are most vulnerable to oxidative damage due to their low antioxidant activity ${ }^{[105]}$. Furthermore, the metabolism of excitatory amino acids and neurotransmitters in neuronal cells further increase the production of ROS and oxidative stress. Therefore, oxidative stress plays vital role in the pathogenesis of neurodegenerative diseases ${ }^{[106]}$.

\section{MODE OF CELL DEATH}

In neuronal cells, calcium ions overload caused by glutamate excitotoxicity activates damaging enzymes for instance phospholipases that produce ROS. ROS induces neuronal injury such as cell membrane disruption, damage to intracellular proteins and DNA, and induction of mitochondrial release of cytochrome $c$, and caspase 
activation. The release of cytochrome $c$, caspase activation and DNA fragmentation are the molecular hallmarks of apoptosis ${ }^{[107-110]}$. Furthermore, cystein protease or calpains are also activated by the elevation of intracellular $\mathrm{Ca}^{2+}$. Calpains cleave various intracellular proteins, such as regulatory protein, membrane channels and cytoskeletal that lead to neuronal cell death by necrosis ${ }^{[11,112]}$.

Apoptosis and necrosis signify 2 significant different cell death mechanisms. Apoptosis, also well-known as programmed cell death or cell suicide, happens under normal physiological conditions. It is an important mechanism in maintaining the homeostasis and regulation of tissue size during postnatal life. Apoptosis is signified by the activation of endogenous endonucleases that are activated directly or indirectly by a cascade of biochemical reactions, which involve cutting of DNA into fragments and consequently causing cell death. Apparently, cells continue to produce proteins and ATP during apoptosis. As a result, each apoptotic body is surrounded by cell membrane which contains intact and functional cell components. Apoptosis causes morphological changes that can be characterized by a deep chromatin condensation and formation of apoptotic bodies, followed by nuclear fragmentation and secondary necrosis that occur at the final stage.

In contrast to apoptosis, necrosis occurs when cells are exposed to extreme variance from physiological condition. It starts with an impairment of the cell's ability to maintain homeostasis. Necrosis can be signified by the loss of metabolic functions and the loss of cell membrane integrity. The cells terminate their proteins and ATP production during necrosis. The morphological changes of necrosis are signified by cell membrane rupture starts with swelling of cytoplasm and mitochondria. Cell membrane ruptures results in the release of the cell's components into the surrounding tissue. This process is recognized as cytolysis. The released cell's components will induce an intense inflammatory response ${ }^{[113-115]}$.

\section{CONCLUSION}

The excessive glutamate-induced neurotoxicity had been associated to many chronic neurodegenerative disorders in CNS. Under normal situation, the astrocyte is responsible in clearing up glutamate from synaptic cleft. Hence, minimizes the neuronal injury from glutamate toxicity. However, excessive glutamate will induce oxidative stress in both astrocyte and neuronal cell and lead to cell death. Studies demonstrated that radical scavengers like vitamin $\mathrm{E}$, in the form of tocopherol and tocotrienol, can protect the glutamate-injured cells from oxidative stress. Other than vitamin E, other sources such as microbial resources were also demonstrating strong antioxidants ${ }^{[16-126]}$ and neuroprotective properties ${ }^{[127-132]}$ such as metal chelating and radical scavenging potentials ${ }^{[133-140]}$. In conclusion, neuronal cell seemed to be the most vulnerable brain cells toward glutamate toxicity. In the absence of astrocyte, neuronal cells are 100-fold more vulnerable to glutamate toxicity. Thus, more studies should be conducted to explore the protective effect of astrocyte on neuronal cell against glutamate toxicity.

\section{Conflict of Interest}

The authors declare that there is no conflict of interest in this work.

\section{Authors Contributions}

The literature review and manuscript writing were performed by H-MY, K-LL and LT-HT.

\section{Reference}

1. Chamberlain D and Swope W, Support of neurological function. In: Elliott D, Aitken L and Chaboyer W. ACCCN's critical care nursing. Marrickville, N.S.W.: Elsevier Australia 2006; 307-366.

2. Stuve $\mathrm{O}$ and Zettl U, Neuroinflammation of the central and peripheral nervous system: An update. Clin Exp Immunol 2014; 175(3): 333-335.

3. Singh I. Textbook of Human Neuroanatomy. (7th ed.). New Delhi: Jaypee Brothers 2006

4. Brodal P. The central nervous system. Structure and Function. (4th ed.) 2010.

5. Michael-Titus AT, Revest P, and Shortland P. The nervous system. (2nd ed.). Canada: Churchill Livingstone 2010.

6. Coombs JS, Curtis DR, and Eccles JC. The generation of impulses in motorneuron. J Physiol 1957; 139: 232-249.

7. Stuart $\mathrm{S}$ and Hausser M. Initiation and spread of sodium action potentials in cerebellar purkinje cells. Neuron 1994; 13(3): 703-712.

8. Jessen KR, Glial cells. Int J Biochem Cell B 2004; 36: 1861-1867.

9. Purves D, Augustine GJ, and Fitzpatrick D. Neuroscience. (2nd ed.). Sunderland (MA): Sinauer Associates 2001.

10. Auld DS and Robitaille R. Glial cells and neurotransmission: An inclusive view of synaptic function. Neuron 2003; 40: 389-400.

11. Walz W, Potassium homeostasis in the brain at the organ and cell level. Adv Mol Cell Biol 2004; 31: 595-609.

12. Gegelashvili G, Dehnes Y, Danbolt NC, et al. The high-affinity glutamate transporters GLT1, GLAST, and EAAT4 are regulated via different signalling mechanisms. Neurochem Int 2000; 37: 163-170.

13. Occhipinti R, Somersalo E, and Calvetti D. Astrocytes as the glucose shunt for glutamatergic neurons at high activity: An in-silico study. J Neurophysiol 2008; 101(5): 2528-2538.

14. Bittner CX, Valdebenito R, Ruminot I, et al. Fast and reversible stimulation of astrocytic glycolysis by $\mathrm{K}^{+}$and a delayed and persistent effect of glutamate. J Neurosci 2011; 31(12): 4709-4713.

15. Maragakis NJ and Rothstein JD. Mechanisms of disease: Astrocytes in neurondegenerative disease. Neurology 2006; 2(12): 679-689.

16. Zonta M, Sebelin A, Gobbo S, et al. Glutamate-mediated cytosolic calcium oscillations regulate a pulsatile prostaglandin release from cultured rat astrocytes. J Physiol 2003; 553(2): 407-414

17. Hansson E and Ronnback L. Glial neuronal signaling in the central nervous system. FASEB J 2003; 17: 341-348.

18. Tabrizi S. Neurodegenerative diseases neurobiology pathogenesis and therapeutics. J Neurol Neurosurg Psychiatry 2006; 77(2): 284.

19. Dibble L. Tracking the natural history of mobility loss in neurodegenerative diseases: Preliminary results using an online database track system. J Neurol Phys Ther 2006; 30(4): 219-220.

20. Price DL, Sisodia SS, and Borchelt DR. Genetic neurodegenerative diseases: The human illness and transgenic models. Science 1998; 282(5391): 1079-1083.

21. Ritz B. Environmental toxins and neurodegenerative diseases: A challenge for epidemiologists. Epidemiology 2006; 17(1): 2-3.

22. Nicolson GL. Chronic bacterial and viral infections in neurodegenerative and neurobehavioral disease. LabMed 2008; 39(5): 291-299.

23. Laskowitz DT, Song PP, Wang HC, et al. Traumatic brain injury exacerbates neurodegenerative pathology: Improvement with an apolipoprotein E-based therapeutic. J Neurotraum 2010: 27: 1983-1995.

24. Ambegaokar SS, Roy B, and Jackson GR. Neurodegenerative models in Drosophila: Polyglutamine disorders, Parkinson disease, and amyotrophic lateral sclerosis. Neurobiol Dis 2010; 40: 29-30.

25. Martin LJ. Mitochondrial and cell death mechanisms in neurodegenerative diseases. Pharmaceuticals 2010; 3: 839-915.

26. Li M, Chen LY, Lee HS, et al., The role of intracellular amyloid $\beta$ in Alzheimer's disease. Prog Neurobiol 2007; 83: 131-139.

27. Cotman CW, Poon WW, Rissman RA, et al. The role of caspase cleavage of Tau in Alzheimer disease neuropathology. J Neuropathol Exp Neurol 2005; 64(2): 104-112.

28. Farkas IG, Czigner A, Farkas E, et al. Beta-amyloid peptide-induced blood-brain barrier disruption facilitates T-cell entry into the rat brain. Acta Histochem 2003; 105(2): 115-125.

29. Tsao N, Hsu HP, Wu CM, et al. Tumour necrosis factor- $\alpha$ causes an increase in blood-brain barrier permeability during sepsis. J Med Microbiol 2001; 50: 812-821.

30. Schaeffer EL and Gattaz WF. Cholinergic and glutamatergic alterations beginning at the early stages of Alzheimer disease: Participation of the 
phospholipase A2 enzyme. Psychopharmacology 2008; 198(1): 1-27.

31. Hirsch E, Graybiel AM and Agid YA. Melanized dopaminergic neurons are differentially susceptible to degeneration in Parkinson's disease. Nature 1988; 334: 345-348.

32. Shulman JM and De Jager PL. Evidence for a common pathway linking neurodegenerative diseases. Nat Genet 2009; 41: 1261-1262.

33. Betarbet R, Sherer TB, and Greenamy JT. Ubiquitin-proteasome system and Parkinson's disease. Exp Neurol 2005; 191: 17-27.

34. Przedborski S. Pathogenesis of nigral cell death in Parkinson's disease. Parkinsonism Relat Disord 2005; 11(1): 3-37.

35. Landles $\mathrm{C}$ and Bates GP. Huntingtin and the molecular pathogenesis of Huntington's disease. EMBO Rep 2004; 5(10): 958-963.

36. Ross CA and Poirier MA. Protein aggregation and neurodegenerative disease. Nat Med 2004; 10: 10-17.

37. Imarisio S, Carmichael J, Korolchuk V, et al. Huntington's disease: From pathology and genetics to potential therapies. J Biochem 2008; 412(2): 191-209.

38. Rao SD, Yin HZ, and Weiss JH. Disruption of glial glutamate transport by reactive oxygen species produced in motor neurons. J Neurosci 2003; 23(7): 2627-2633.

39. Barnham KJ, Masters CL, and Bush AI, Neurodegenerative diseases and oxidative stress. Nat Rev Drug Discov 2004; 3(3): 205-214.

40. Rebecca CB, Alan HL, and Babasaheb RS. Neurodegenerative disease: An overview of environmental risk factors. Environ Health Perspect 2005; 113(9): 1250-1256.

41. Pekny $\mathrm{M}$ and Nilsson $\mathrm{M}$. Astrocyte activation and reactive gliosis. Glia 2005; 50(4): 427-434.

42. Ridet JL, Malhotra SK, Privat A, et al. Reactive astrocytes: Cellula and molecular cues to biological function. Trends in Neuroscience 1997; 20(12): 570-577.

43. Li C, Zhao $\mathrm{R}$, Gao $\mathrm{K}$, et al., Astrocytes: Implications fo neuroinflammatory pathogenesis of Alzheimer's disease. Curr Alzheimer Res 2011; 8(1): 67-80.

44. Francois B, Claire B, Cecile B, et al. Metabolism and functions of L-glutamate in the epithelial cells of small and large intestines. Am J Clin Nutr 2009; 90(3): 814-821.

45. Hudspith MJ, Glutamate: A role in normal brain function, anesthesia, analgesia and CNS injury. Br J Anaesth 1997; 78: 731-747.

46. Prinsen H, de Graaf RA, Mason GF, et al. Reproducibility measurement of glutathione, GABA, and glutamate: Towards in vivo neurochemical profiling of multiple sclerosis with MR spectroscopy at 7 Tesla. J Magn Reson Imaging 2017; 45(1): 187-198.

47. Crupi R, Impellizzeri D, and Cuzzocrea S. Role of metabotropic glutamate receptors in neurological disorders. Front Mol Neurosci 2019; 12(20): doi: 10.3389/fnmol.2019.00020

48. Pin JP and Duvoisin R. The metabotropic glutamate receptors: structure and functions. Neuropharmacology 1995 34(1): 1-26.

49. Shigemoto R, Kinoshita A, Wada E, et al. Differential presynaptic localization of metabotropic glutamate receptor subtypes in the rat hippocampus. J Neurosci 1997; 17(19): 7503-7522.

50. Teichberg VI. Glial glutamate receptors: Likely actors in brain signaling. FASEB J 1991; 5: 3086-3091.

51. Steinhauser C and Gallo V. News on glutamate receptors in glial cells. Trends Neurosci 1996; 19(8): 339-345.

52. Farrant $\mathrm{M}$ and Kaila $\mathrm{K}$. The cellular, molecular and ionic basis of GABA(A) receptor signaling. Prog Brain Res 2007; 160: 59-87.

53. Jong YJI, Kumar V, Kingston AE, et al. Functional metabotropic glutamate receptors on nuclei from brain and primary cultured striata neurons role of transporters in delivering ligand. J Biol Chem 2005; 280: 30469-30480.

54. Danbolt NC. Glutamate uptake. Prog Neurobiol 2001; 65: 1-105

55. Wadiche, J.I., Amara, S.G. and Kavanaugh, M.P. (1995). Ion fluxes associated with excitatory amino acid transport. Neuron. 15(3): 721728

56. Hu WH, Walters WM, Xia XM, et al. Neuronal glutamate transporter EAAT4 is expressed in astrocytes. Glia 2003; 44(1): 13-25.

57. Gegelashvili G, Danbolt NC, and Schousboe A, Neuronal soluble factors differentially regulate the expression of the GLT1 and GLAST glutamate transporters in cultured astroglia. J Neurochem 1997; 69(6): 2612-2615.

58. Palmer MJ, Taschenberger H, Hull C, et al. Synaptic activation of presynaptic glutamate transporter currents in nerve terminals. J Neurosci 2003; 23(12): 4831-4841.

59. Maeda S, Kawamoto A, Yatani Y, et al. Gene transfer of GLT-1, a glia glutamate transporter, into the spinal cord by recombinant adenovirus attenuates inflammatory and neuropathic pain in rats. Mol Pain 2008; 4(65).

60. Plakidou-dymock S and McGivan JD. Regulation of the glutamate transporter by amino acid deprivation and associated effects on the level of EAAC1 mRNA in the renal cell line NBL-1. J Biochem 1993 295: 749-755.

61. Lo M, Wang YZ, and Gout PW. The $\mathrm{x}(\mathrm{c})$-cystine/glutamate antiporter A potential target for therapy of cancer and other diseases. J Cell Physiol 2008; 215(3): 593-602.

62. Jinap $\mathrm{S}$ and Hajeb P. Glutamate. Its applications in food and contribution to health. Appetite 2010; 55: 1-10.

63. Sonnewald $\mathrm{U}, \mathrm{Qu} \mathrm{H}$, and Aschner M. Pharmacology and toxicology of astrocyte-neuron glutamate transport and cycling. J Pharmacol Exp Ther 2002; 301(1): 1-6

64. Anwyl R. Metabotropic glutamate receptors: Electrophysiological properties and role in plasticity. Brain Res Rev 1999, 29: 83-120.

65. Mahmoud S, Gharagozloo M, Simard C, et al. Astrocytes maintain glutamate homeostasis in the CNS by controlling the balance between glutamate uptake and release. Cells 2019; 8(2): 124.
66. Suarez I, Bodega G, and Fernandez B. Glutamine synthetase in brain Effect of ammonia. Neurochem Int 2002; 41(2-3): 123-142.

67. Broer S and Brookes N. Transfer of glutamine between astrocytes and neurons. J Neurochem 2001; 77: 706-719.

68. Mackenzie B, Schafer MKH, Erickson JD, et al. Glutamine transporte SNAT1 support special roles in central neurons. J Biol Chem 2003; 278(26): 23720-23730.

69. Stanley CA, Regulation of glutamate metabolism and insulin secretion by glutamate dehydrogenase in hypoglycemic children. Am J Clin Nutr 2009; 90(3): 862-866.

70. Pellerin L and Magistretti PJ. Glutamate uptake into astrocytes stimulates aerobic glycolysis: a mechanism coupling neuronal activity to glucose utilization. Proc Natl Acad Sci 1994, 91: 10625-10629.

71. Ottersen OP, Lake JH, Reichelt W, et al. Ishemic disruption of glutamate homeostasi in brain: Quantitative immunocytochemical analyses. J Chem Neuroanat 1996; 12(1): 1-14.

72. Meldrum BS, Glutamate as a neurotransmitter in the brain: Review of physiology and pathology. J Nutr 2000; 130(4): 1007-1015.

73. Schinder AF, Olson EC, Spitzer NC, et al. Mitochondrial dysfunction is a primary event in glutamate neurotoxicity. J Neurosci 1996; 16(19): 6125-6133.

74. Kelsey N, Wilkins H, and Linseman D. Nutraceutical antioxidants as novel neuroprotective agents. Molecules 2010; 15(11): 7792-7814.

75. Hayashi T. A physiological study of epileptic seizures following cortica stimulation in animals and its application to human clinics. Jpn J Physiol 1952; 3(1): 46-64.

76. Hayashi T. Effects of sodium glutamate on nervous system. Keio J Med 1954; 3: 192-193.

77. Lucas DR and Newhouse JP. The toxic effect of sodium L-glutamate on the inner layers of the retina. Arch Ophthalmol 1957; 58(2): 193-201.

78. Olney JW. Brain lesions, obesity, and other disturbances in mice treated with monosodium glutamate. Science 1969; 164(3880): 719-721.

79. Mark LP, Prost RW, Ulmer JL, et al. Pictorial review of glutamate excitotoxicity: Fundamental concepts for neuroimaging. Am J Neuroradiol 2001; 22: 1813-1824.

80. Schapansky J, Morissette M, Odero G, et al., Neuregulin beta1 enhances peak glutamate-induced intracellular calcium levels through endoplasmic reticulum calcium release in cultured hippocampal neurons. Can Physiol Pharmacol 2009; 87(10): 883-891.

81. Bardo S, Cavazzini MG, and Emptage N. The role of the endoplasmic reticulum $\mathrm{Ca} 2+$ store in the plasticity of central neurons. Trends Pharmacol Sci 2006; 27(2): 78-84.

82. Blaustein MP and Lederer WJ. Sodium/calcium exchange: Its physiological implications. Physiol Res 1999; 79(3): 76-854.

83. Nicholis DG and Budd SL. Mitochondria and neuronal survival. Physiol Rev 2000; 80(1): 315-360.

84. Millanvoye-Van BE, David-Dufilho M, Pham TD, et al. Regulation of arachidonic acid release by calcium influx in human endothelial cell. J Vasc Res 1999; 36(3): 235-244.

85. Guibert C, Marthan R and Savineau J. 5-HT induces an arachidonic acidsensitive calcium influx in rat small intrapulmonary artery. Am J Physiol Lung Cell Mol Physiol 2004; 286(6): 1228-1236.

86. Yagami $\mathrm{T}$, Ueda $\mathrm{K}$, Asakura $\mathrm{K}$, et al. Human group IIA secretory phospholipase A2 potentiates $\mathrm{Ca}^{2+}$ influx through L-type voltagesensitive $\mathrm{Ca}^{2+}$ channels in cultured rat cortical neurons. J Neurochem 2003; 85(3): 749-758.

87. Skarka and Ostadal B. Mitochondrial membrane potential in cardiac myocytes. Physiol Res 2002; 51: 425-434.

88. Abramov AY and Duchen MR. Mechanisms underlying the loss of mitochondrial membrane potential in glutamate excitotoxicity. (BBA)Bioenergetics 2008; 1777(7-8): 953-964

89. Oh SH and Lim SC. A rapid and transient ROS generation by cadmium triggers apoptosis via caspase-dependent pathway in HepG2 cells an this is inhibited through $\mathrm{N}$-acetylcysteine mediated catalase upregulation. Toxicol Appl Pharmacol 2006; 212(3): 212-223.

90. Susin SA, Lorenzo HK, Zamzami N, et al. Molecular characterization of mitochondrial apoptosis-inducing factor. Nature 1999; 397(6718): 441-446.

91. Li YH, Maher P, and Schubert D. Phosphatidylcholine-specific phospholipase $\mathrm{C}$ regulates glutamate-induced nerve cell death. Proc Nat Acad Sci 1998; 95: 7748-7753.

92. Murphy TH, Miyamoto M, Sastre A, et al Glutamate toxicity in a neuronal cell line involves inhibition of cystine transport leading to oxidative stress. Neuron 1989; 2(6): 1547-1558.

93. Wang H, Li J, Follett PL, et al. 12-Lipoxygenase plays a key role in cell death caused by glutathione depletion and arachidonic acid in rat oligodendrocytes. Eur J Neurosci 2004; 20(8): 2049-2058.

94. Seiler A, Schneider M, Forster H, et al. Glutathione peroxidase 4 senses and translates oxidative stress into 12/15-lipoxygenase dependent- and AIF-mediated cell death. Cell Metab 2008; 8: 237-248

95. Pallast S, Arai K, Wang XY, et al. 12/15-Lipoxygenase targets neurona mitochondria under oxidative stress. J Neurochem 2009; 111(3): 882-889

96. Pallast S, Arai K, Pekcec A, et al. Increased nuclear apoptosis-inducing factor after transient focal ischemia: A 12/15-lipoxygenease-dependent organelle damage pathway. J Cerebr Blood F Met 2010; 30(6): 11571167.

97. McCord JM. The evolution of free radicals and oxidative stress. Am J Med 2000; 108(8): 652-659.

98. Fang YZ, Yang S, and Wu GY. Free radicals, antioxidants, and nutrition. Nutrition 2002; 18(10): 872-879.

99. Goswami SK, Maulik $\mathrm{N}$ and Das DK. Ischemia-reperfusion and cardio protection: A delicate balance between reactive oxygen species generation and redox homeostasis. Ann Med 2007; 39: 275-289.

100. Matsuzaki S, Szweda PA, Szweda LI, et al. Regulated production of free 
radicals by the mitochondrial electron transport chain: cardiac ischemic preconditioning. Adv Drug Deliv Rev 2009; 61(14): 1324-1331.

101. Cadenas E and Davies KJA. Mitochondril free radical generation, oxidative stress, and aging. Free Radic Biol Med 2000; 29(3-4): 222230.

102. Turrens JF. Mitochondrial formation of reactive oxygen species. J Physiol 2003; 552: 335-344.

103. Devi GS, Prasad MH, Saraswathi I, et al. Free radical antioxidant enzymes and lipid peroxidation in different types of leukaemia. Clin Chim Acta 2000; 293(1-2): 53-62.

104. Aksenova MV, Aksenov MY, Mactutus CF, et al. Cell culture models of oxidative stress and injury in the central nervous system. Curr Neurovasc Res 2005; 2: 73-89.

105. Floyd RA and Carney JM. Free radical damage to protein and DNA: Mechanisms involved and relevant observations on brain undergoing oxidative stress. Ann Neurol 1992; 32: 22-27.

106. Gilgun-Sherki Y, Melamed E, and Offen D. Oxidative stress inducedneurodegenerative diseases: The need for antioxidants that penetrate the blood brain barrier. Neuropharmacology 2001; 40(8): 959-975.

107. Mattson MP. Excitotoxicity and excitoprotective mechanisms: Abundant targets for the prevention and treatment of neurodegenerative disorders. Neuromolecular Med 2003;3(2): 65-94.

108. Annunziato L, Amoroso S, Pannaccione A, et al. Apoptosis induced in neuronal cells by oxidative stress: Role played by caspases and intracellular calcium ions. Toxicology 2003; 139: 125-133.

109. Nicholls DG, Mitochondrial dysfunction and glutamate excitotoxicity studied in primary neuronal culture. Curr Mol Med 2004; 4(2): 149177.

110. Fan TJ, Han LH, Cong RS, et al. Caspase family protease and apoptosis. Acta Biochim Biophys Sin 2005, 37(11): 719-727.

111. Hou ST and MacManus JP. Molecular mechanisms cerebral ischemiainduced neuronal cell death. Int Rev Cytol 2002; 221: 93-148.

112. Boujrad H, Gubkina O, Robert N, et al. AIF-mediated programmed necrosis. Cell Cycle 2007; 6(21): 2612-2619.

113. Vitale M, Zamai L, Mazzotti G, et al. Differential kinetics of propidium iodide uptake in apoptotic and necrotic thymocytes. Histochemistry 1993; 100: 223-229.

114. Nanji AA and Hiller-Sturmhofel S, Apoptosis and Necrosis. Alcohol Res Health 1997; 21(4): 325-330.

115. Zhivotosky B and Orrenius S. Assessment of apoptosis and necrosis by DNA fragmentation and morphological criteria. Curr Protoc Cell Biol 2001; 18(3): 1-23

116. Law, JW-F, Ser, H-L, Ab Mutalib, N-S, et al. Streptomyces monashensis sp. nov., a novel mangrove soil actinobacterium from East Malaysia with antioxidative potential. Sci Rep, 2019; 9(1): 3056

117. Ser, H-L, Tan, W-S, Ab Mutalib, N-S, et al. Draft genome sequence of mangrove-derived Streptomyces sp. MUSC 125 with antioxidant potential. Front Microbiol, 2016; 7: 1470.

118. Ser, H-L, Tan, LT-H, Law, JW-F, et al. Focused review: Cytotoxic and antioxidant potentials of mangrove-derived Streptomyces. Front Microbiol, 2017; 8: 2065.

119. Tan, LTH, Mahendra, CK, Yow, YY, et al. Streptomyces sp. MUM273b: A mangrove $\square$ derived potential source for antioxidant and UVB radiation protectants. MicrobiologyOpen, 2019: e859.

120. Ser, H-L, Palanisamy, UD, Yin, W-F, et al. Presence of antioxidative agent, Pyrrolo [1, 2-a] pyrazine-1, 4-dione, hexahydro-in newly isolated Streptomyces mangrovisoli sp. nov. Front Microbiol, 2015; 6: 854.

121. Ser, H-L, Yin, W-F, Chan, K-G, et al. Antioxidant and cytotoxic potentials of Streptomyces gilvigriseus MUSC $26^{\mathrm{T}}$ isolated from mangrove soil in Malaysia. Prog Microbes Mol Biol, 2018; 1(1): a0000002.

122. Ser, H-L, Tan, W-S, Ab Mutalib, N-S, et al. Genome sequence of Streptomyces pluripotens MUSC $135^{\mathrm{T}}$ exhibiting antibacterial and antioxidant activity. Mar Genomics, 2015; 24: 281-283.

123. Lee, L-H, Zainal, N, Azman, A-S, et al. Streptomyces pluripotens sp. nov., a bacteriocin-producing streptomycete that inhibits meticillinresistant Staphylococcus aureus. Int J Syst Evol Microbiol, 2014; 64(9): 3297-3306.

124. Ser, H-L, Ab Mutalib, N-S, Yin, W-F, et al. Genome sequence of Streptomyces antioxidans MUSC $164^{\mathrm{T}}$ isolated from mangrove forest. Prog Microbes Mol Biol, 2018; 1(1): a0000001.

125. Law, JW-F, Chan, K-G, He, Y-W, et al. Diversity of Streptomyces spp. from mangrove forest of Sarawak (Malaysia) and screening of their antioxidant and cytotoxic activities. Sci Rep, 2019; 9(1): 1-15.

126. Ser, H-L, Chan, K-G, Tan, W-S, et al. Complete genome of mangrovederived anti-MRSA streptomycete, Streptomyces pluripotens MUSC 135 ${ }^{\mathrm{T}}$. Prog Microbes Mol Biol, 2018; 1(1): a0000004.

127. Azman, A-S, Othman, I, Fang, C-M, et al. Antibacterial, anticancer and neuroprotective activities of rare Actinobacteria from mangrove forest soils. Indian J Microbiol, 2017; 57(2): 177-187.

128. Ser, H-L, Tan, LT-H, Palanisamy, UD, et al. Streptomyces antioxidans sp. nov., a novel mangrove soil actinobacterium with antioxidative and neuroprotective potentials. Front Microbiol, 2016; 7: 899

129. Law, JW-F, Pusparajah, P, Ab Mutalib, N-S, et al. A Review on Mangrove Actinobacterial Diversity: The Roles of Streptomyces and Novel Species Discovery. Prog Microbes Mol Biol, 2019; 2(1): a00000024.

130. Lee, L-H, Chan, K-G, Stach, J, et al. The search for biological active agent (s) from actinobacteria. Front Microbiol, 2018; 9: 824.

131. Ser, H-L, Palanisamy, UD, Yin, W-F, et al. Streptomyces malaysiense sp. nov.: A novel Malaysian mangrove soil actinobacterium with antioxidative activity and cytotoxic potential against human cancer cell lines. Sci Rep, 2016; 6(1): 1-12.

132. Law, JW-F, Letchumanan, V, Tan, LT-H, et al. The Rising of "Modern Actinobacteria" Era. Prog Microbes Mol Biol, 2020; 3(1): a00000064.

133. Kemung, HM, Tan, LT-H, Chan, K-G, et al Investigating the antioxidant potential of Streptomyces sp. MUSC 11 from mangrove soil in Malaysia. Prog Drug Discov Biomed Sci, 2019; 2(1).

134. Ser, H-L, Ab Mutalib, N-S, Yin, W-F, et al. Evaluation of antioxidative and cytotoxic activities of Streptomyces pluripotens MUSC 137 isolated from mangrove soil in Malaysia. Front Microbiol. 2015; 6: 1398

135. Tan, LT-H, Ser, H-L, Yin, W-F, et al. Investigation of antioxidative and anticancer potentials of Streptomyces sp. MUM256 isolated from Malaysia mangrove soil. Front Microbiol, 2015; 6: 1316.

136. Tan, LT-H, Chan, K-G, Chan, CK, et al. Antioxidative potential of a Streptomyces sp. MUM292 isolated from mangrove soil. Biomed Res Int, 2018; 2018: 4823126

137. Kemung, HM, Tan, LT-H, Chan, K-G, et al. Antioxidant activities of Streptomyces sp. strain MUSC 14 from mangrove forest soil in Malaysia. Biomed Res Int, 2020; 2020: 6402607

138. Tan, LT-H, Chan, K-G, Khan, TM, et al. Streptomyces sp. MUM212 as a source of antioxidants with radical scavenging and metal chelating properties. Front Pharmacol, 2017; 8: 276.

139. Law, JW-F, Ser, H-L, Duangjai, A et al. Streptomyces colonosanans sp. nov., a novel actinobacterium isolated from Malaysia mangrove soil exhibiting antioxidative activity and cytotoxic potential against human colon cancer cell lines. Front Microbiol, 2017; 8: 877.

140. Tan, LT-H, Chan, K-G, Pusparajah, P, et al. Mangrove derived Streptomyces sp. MUM265 as a potential source of antioxidant and anticolon-cancer agents. BMC Microbiol, 2019; 19(1): 38. 